\title{
Development of Online Teachers-Student Consultation Application
}

https://doi.org/10.3991/ijim.v14i08.11284

Eliza B. Ayo, $\left({ }^{\bowtie}\right)$, Diane Montero

Centro Escolar University, Manila, Philippines

ebayo@ceu.edu.ph

Dianne Dote

St. Jude College, Manila, Philippines

Liza Villanueva

Our Lady of Perpetual Help, Manila, Philippines

Celia Verano

Arellano University, Manila, Philippines

\begin{abstract}
This research presents the development of online teachersstudents consultation application. A need assessment was conducted to determine what subjects, which activities, respondents' preference and attitude towards face-to-face and online consultation. These gathered data were treated using the descriptive method while the v-model was used during the development cycle. Java, web services and several web technologies installed in computer with i3 processor, 4GB DDR III RAM and with 500GB hard drive were the tools utilized in the application. Essentially, the study was able to develop an alternative to the traditional way of meeting the students physically to address academic difficulties, curricular and extra-curricular needs.
\end{abstract}

Keywords - Consultation application, online meet ups, addressing academic difficulties, virtual meeting.

\section{Introduction}

Allocating an extra time and responsiveness to students beyond classroom hour are two of the qualities a great teacher embodies. The presence of a mentor to lend a helping hand no matter how small or big the scale is, is sealed to them by virtue of their profession. Thus, scheduling consultation hour is deemed necessary. It is a valueadded service beyond classrooms hour for the students to seek assistance on academic, curricular and extra-curricular related concerns. The aim of consultation is to help students cope with lessons, intensify learning and complete the needed task beyond classroom hours or as simple as sharing to their teachers what bothers them. This 
usually lasts for an hour depending on the degree to which they need help and the expertise of the teachers on the topic at hand.

A sudden changed in behavior, a more engaged students on his academics, motivated individuals and increase score to test and quizzes are examples of desirable outcomes teachers expect among students to measure effectiveness of this program. These outcomes could be used to determine which lessons need to be strengthened as part of an intervention program plan to low performing students. The exact reason why schools and universities are implementing it as an academic service and in compliance with the rules and regulations of different accrediting bodies [1].

The technical feasibility of online consultation is possible because of the proliferation of software and hardware that supports it. With 4.77 billion estimated number of mobile users this 2017, [2] reveals that adapting to technology requires less skills and effort. In fact, there are schools that allow electronic communication to address students' needs aside from meeting them face-to-face [3]. Certainly, in the prevalence of modern technology, process automation is deemed necessary.

This study did not compare nor identify strengths and limitations of which is better with or without technology. The developed Online Teachers-Student Consultation Application simply presents as an alternative in conducting consultation hours based on the student needs and the scope to which process could be automated.

\section{Objectives of the Study}

The objective of this study is to design and develop an online consultation application for students to assist them in their academic difficulties. It also seeks to:

1. Determine students' preferences on where the developed software be applied

2. Automate a process to present an alternative way on addressing students need on academic, curricular and extra-curricular.

3. Provide needed data that may be used for faculty rating, curriculum evaluation and intervention programs.

\section{$3 \quad$ Methodology}

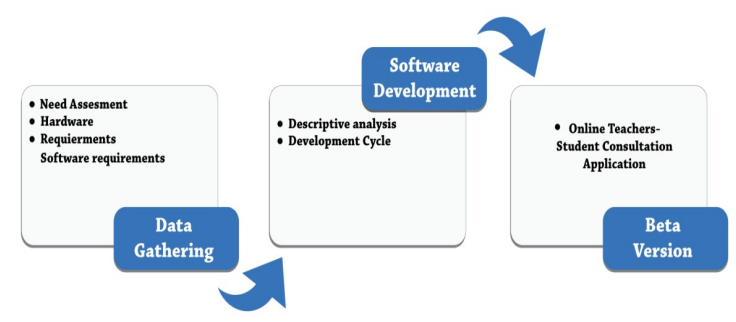

In order to come up with the On-line Teachers Student Consultation Application, a need assessment using the triangulation approach was conducted in Centro Escolar 
University 2nd semester of School Year 2016-2017. To get the needed sample, out of 500 students from various courses, the researcher used Sloven's formula with 5\% degree of error. The stratified random sampling technique was used in the selection of the respondents to ensure that the number of respondents from different campuses is proportional to the overall population. The researcher used two hundred twenty-two (222) students to answer the survey questionnaire and selected a few students for interview to verify and confirm data needed for this study. However, the researcher used random sampling to get the fifty (50) respondents. To determine internal consistency and reliability of a data, a test run was administered to fifteen (15) samples, a Chronbach's Alpha score of .904 was yielded. The descriptive method derived from quantitative and qualitative treatments were applied to the data collected to come up with the needed assessments.

In the need assessments it sought to determine the profile of the respondents in terms of degrees, preferences on what course to apply the software and the attitude towards face to face and an online application in consulting their teachers in their academic, curricular and extra-curricular. Descriptive statistics were used to analyze quantitative data gathered during the needs assessment.

The data gathered were used as a basis in the development of online teachersstudent application using the v-model as a framework in the software development.

\section{Software Development Model}

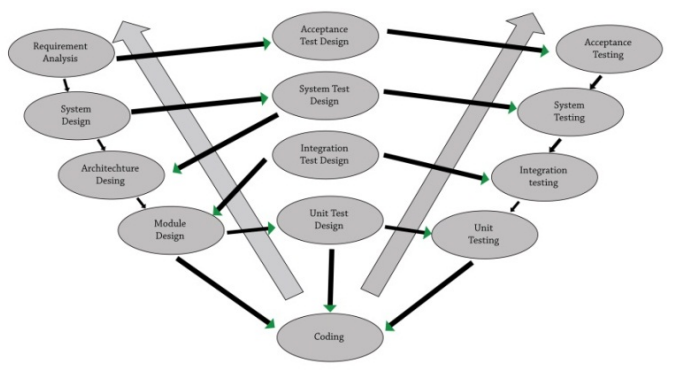

Fig. 1. V-Shaped Model

Online teacher-students consultation application backbone is a product of software development life cycle using V-Shaped model (see Figure 1). This model fits the requirement because at each stage, there is a directly associated testing before proceeding to the next phase [4]. Every stage, a thorough review of the codes and verification from the client on its output is performed before proceeding to the next until system implementation is reached.

Moreover, in this model, the flow of control is iterative. This allows the developer to return to the previous stage if necessary. Since this model provides an earlier feed- 
back, review as well as evaluation of the requirements from the users is the upfront monitoring of quality. This ensures that quality software product is produced.

\section{Technology Used}

The online teacher-student consultation application is a combination of various software and hardware technologies. During the development of the system, JAVA was used as a programming language while J2EE and J2SE in Eclipse IDE were employed as back end programs. For the design of the front end, web technologies such as JAVA SERVLET, JSP, HTML, CSS, JAVASCRIPT, AJAX, JQUERY, DATATABLES AND BOOTSTRAP were utilized. In addition, MYSQL for the database and JBOSS served as the application server for running the web service. Lastly, PUTTY was used to access the Cloud technology for the deployment and storage of the system. As for hardware needs, the developer employed a computer unit equipped with Windows 8 Operating System, i3 processor, 4GB DDR III RAM with $500 \mathrm{~GB}$ hard drive correspondingly.

Determining user requirements and the technology available to support the development of the application are important factor for the success of this study as confirmed by the recent findings that combining user profile and personalization of design methods are two important elements in the development of an activity to be embedded as a design solution [5].

\section{Results and Discussion}

\subsection{Profile of the respondents according to degrees}

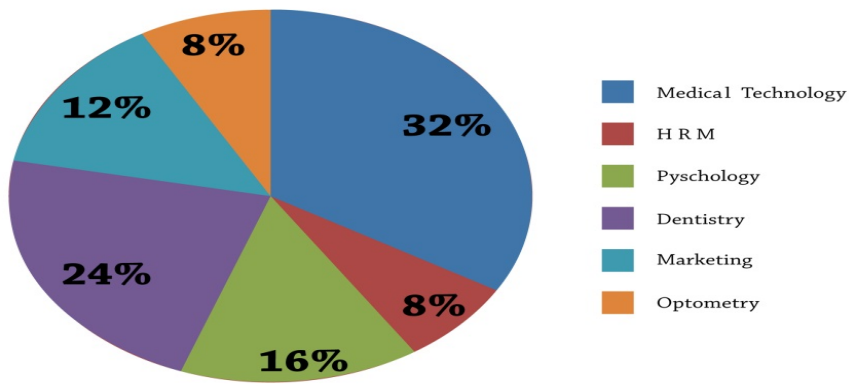

Fig. 2. Profile of the Respondents According to Degrees

A total of fifty (50) respondents were interviewed and surveyed to come up with the needed data for this study. Majority of the respondents are female and in the 3rd year tertiary level. Thirty-two (32\%) are taking up Medical Technology followed by 
Dentistry (24\%). The least in number is enrolled in Optometry and Hotel and Restaurant Management which yielded the same results (8\%). Identifying the course of the respondents is important to determine the need for process automation on various degree programs.

\subsection{Students Preference on where to apply consultation application}

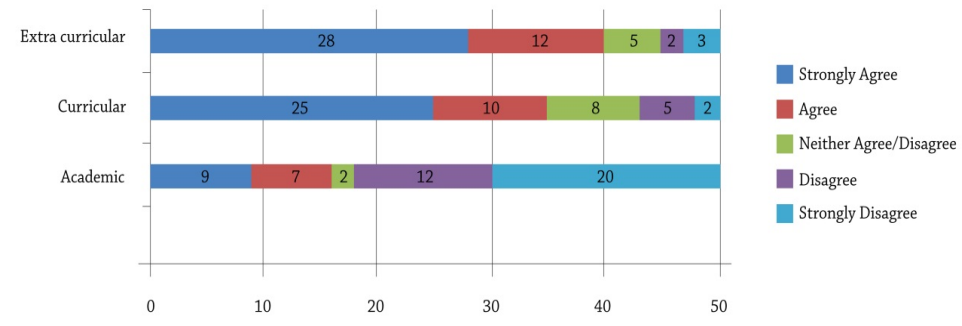

Fig. 3. Students Preference on Where to Apply Consultation Application

The data in Figure 3 suggest that the students preferred online consultation app in their extra-curricular and curricular needs with a majority of the respondents replies that fell on agree to strongly agree. Queries on extra-curricular consisted of events and activities of student council or organization where the students are affiliated in while curricular needs covered questions with regard to school policies process and deadlines. On the other hand, a bigger portion of the respondents' answers belonged to disagree to strongly disagree to address their academic difficulties. Academic concerns dealt with the help needed for specific subjects enrolled. The data imply that for extra-curricular and curricular matters, respondents believed that an application could be used to help them. It is important to identify students' preference because digital transformation can be a negative factor if not address carefully. [6]

\subsection{Consultation method preference per subject}

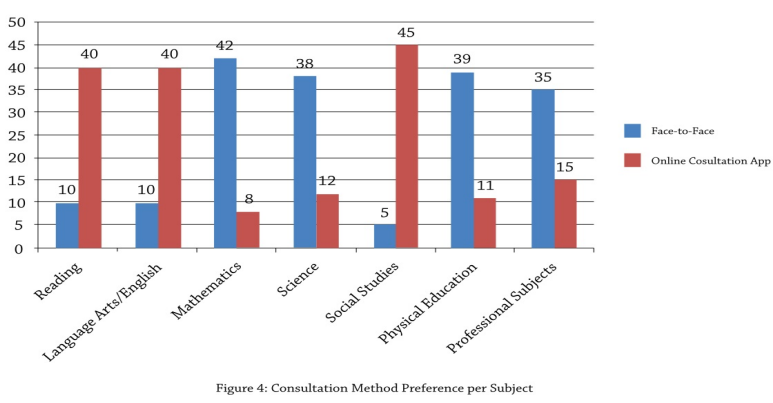

Fig. 4. Consultation Method Preference per Subject 
To determine the extent on where online consultation application could be applied, the lists of subjects were included in the questionnaire. As seen in Figure 4, the students still preferred face-to-face in conducting consultations in their Professional, Mathematics, Science and Physical Education subjects. Subjects such as Reading, Language and Social Studies are were the students prefer online consultation application. This supports that an application like teleconsultation has a positive impact as an educational influence to the user [7] as well as using collaborative tool can help improve their academic performance [8]. This data also reflect that teachers handling these subjects may use online consultation application as an alternative to address the needs of their students and schedule appointment to those that still need physical meet up to maximize time and productivity.

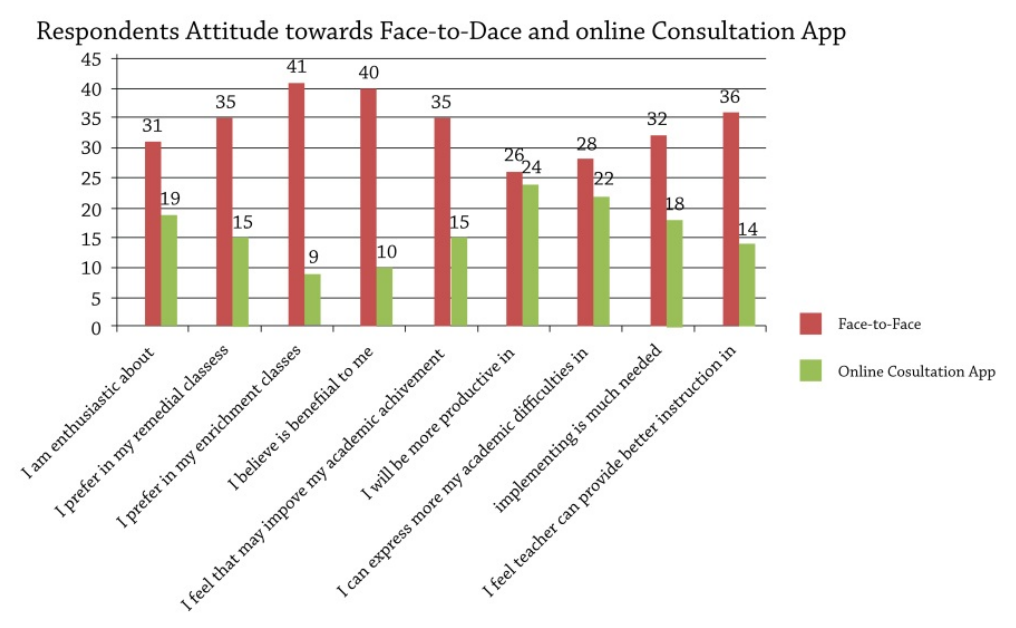

Fig. 5. Respondents Attitude towards Face-to-Face and Online Consultation App

The results of the respondents' attitude towards face-to-face and online consultation application were also examined. As shown in Figure 5, majority of the respondents still preferred face-to-face consultation. A slight difference between the two methods was associated with in terms of productivity and expressing their difficulties. Though the number suggests in favor with physical meet ups, there are still students who would like to try online consultation application. In medical field the teleconsultation application is accepted by fifty $(50 \%)$ of patient without any requirements for further specialist [9]. Undoubtedly, teachers could provide schedule for the two modalities and students get to choose the one appropriate for them to address their specific concerns. This validates that the use of mobile learning has provided a new learning experience for teachers and parents to teach children [10]. 


\section{$7 \quad$ How Does It Work?}

The following use cases describe what tasks could be performed by the user on the application. The illustration shows the presence of module to do task to perform consultation. This confirms that procedures are more automatable when the processes are well defined [11].

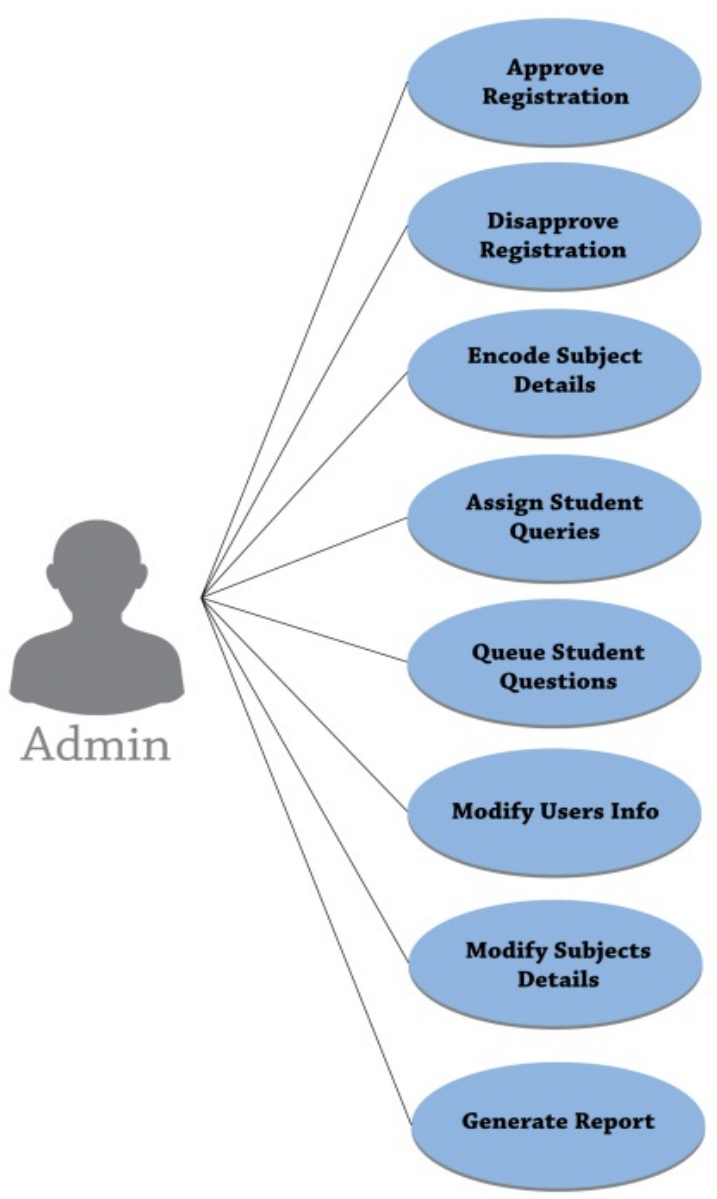

Fig. 6. Use Case Diagram - Administrator Role

This use case (see Figure 6) describes the functions of an administrator. Upon receiving the registration requests of both faculty and students, the administrator will approve or disapprove such requests. All information received during registration can be modified as well as the encoded subject details. This information will be viewed by students and teachers for their perusal. After the students send a message (academic, curricular and or extra-curricular), to their teachers, the administrator queues the que- 
ry to the assigned teachers. A report may then be generated containing teachers' ratings for documentation purposes. Automating process like this will free people from doing repetitive tasks, increasing their productivity and there is $24 \mathrm{X} 7$ availability of service [12].

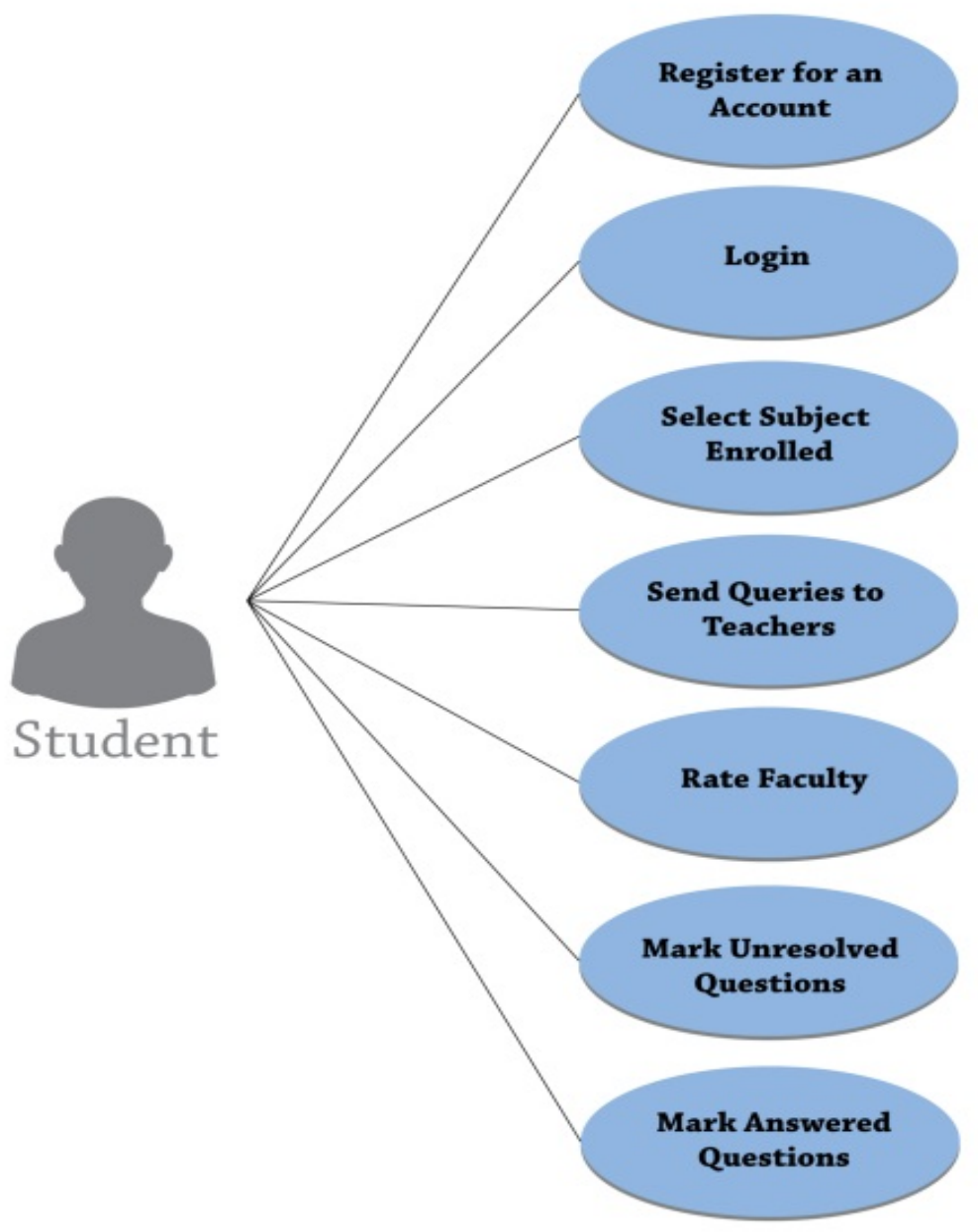

Fig. 7. Use Case Diagram - Student Role

Meanwhile, to initiate the access of the students to the application, an approved registration is needed as seen in this use case (see Figure 7). Username and password serve as the key to log-in to the system which is part of the requirements during registration. Once the students gain access to the system, they select the subject and send queries to the assigned teacher on either academic, curricular and extra-curricular concerns. The students can mark questions whether they were answered or still unre- 
solved and then rate the faculty as regards his or her ability to deal with their issues. For those questions that were marked unresolved, this will be lined up again by the administrator accordingly and may be assigned to a different teacher until students become satisfied with the responses.

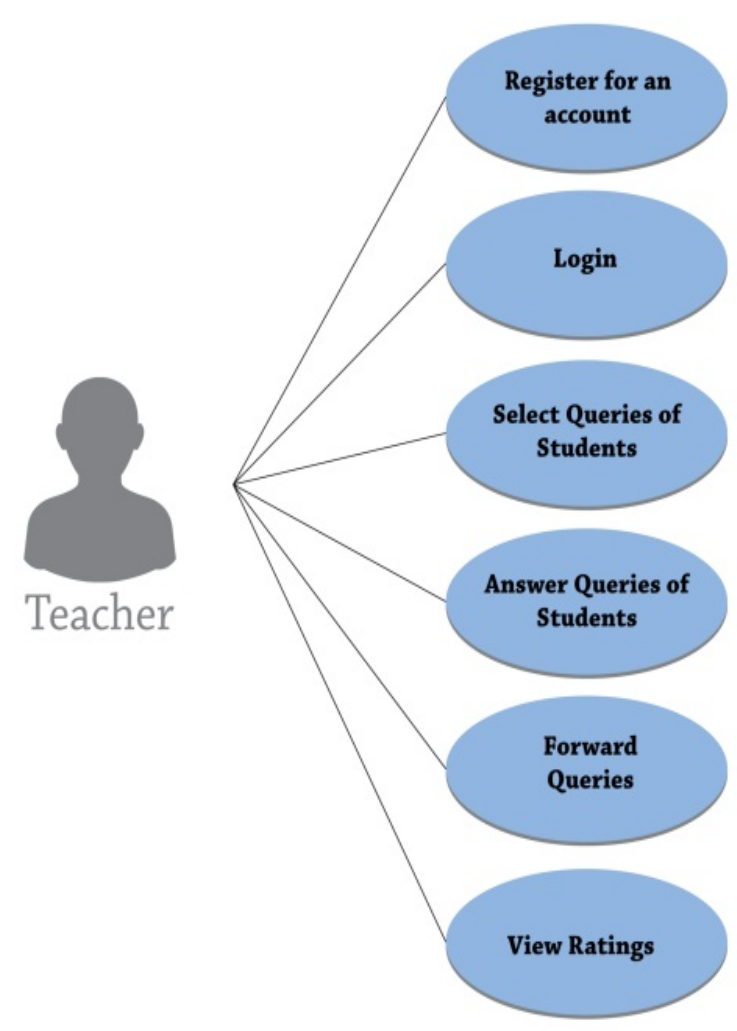

Fig. 8. Use Case Diagram - Teacher Role

Similarly, teachers need to register to get access to the application as seen in this use case (see Figure 4). A valid username and password is needed to use the system. The teacher will then select their subjects, answer queries of the students and forward queries to another teacher if his or her knowledge is inadequate on the topic at hand. The teacher can likewise view the ratings given by the students.

\section{Contribution to Scholarship}

Currently, there is no existing online consultation application dedicated for teachers and students. Most consultation application was for clinical use to solve geograph- 
ical distance between patient and health care providers [13]. In education sector, some schools used teleconsultation to support children with disabilities [14] but not as a way to assist students in their academic difficulties as a common tool for all. This interactive and innovative software application truly encourages collaboration of the faculty to another faculty to help students with their needs varying from academic, curricular and extracurricular. Additionally, the software provides data that when mining techniques were applied; it could present information for faculty efficiency based on the ratings provided. This can serve as a substantial basis for curriculum evaluation as well in accordance with the queries that commonly appear among students. More importantly, an intervention program for those identified students who need habitual assistance may be developed to help them cope with their various needs.

On the administrative side, the user has full control of the system including those functions that the programmer does during maintenance like archiving of records. Since all the softwares that will be used to come up with the application from the design as well as the data base and backend tools were open source, the application will work in any operating system and browsers.

In the implementation stage, a cloud computing solution provider that can offer at least 4 core processor, $16 \mathrm{~GB}$ of memory, $320 \mathrm{~GB}$ of SSD and 6TB of data transfers is the best hardware requirements to consider. An adequate technical support, the rightful owner of the application and the data have to be clearly stipulated in the contract before, during and after new version is uploaded or another cloud provider is employed. Moreover, the current app is well supported should its integration for mobile app and other platforms in the future may be required.

\section{Conclusion}

Using the results of the needs assessment, the features of the developed application respond to different types of queries which were categorized into extra-curricular, curricular and academic. The students have expressed their willingness to use the app to inquire on school policies, processes, activities and events. While the results of the survey reveal that this application will not replace the traditional physical meet ups for their academic needs, subjects like Reading, Language and Social Science were identified on where it could be beneficial. This online teacher-student consultation application promises a new alternative in addressing the concerns of students. For future studies, the output generated by this app when data mining technique is applied could provide information on faculty efficiency, curriculum evaluation and intervention program.

To Access the procedures on how to use the application the following videos are posted via You tube:

Online Consultation App -- Account Registration

https://youtu.be/VUC5dAOnFIU

Online Consultation App -- Admin Process Video

https://youtu.be/BMqBRHf3EVY

Online Consultation App -- Process Flow Video 
https://youtu.be/yV5s2fXfdtg

Online Consultation App --Student Process Video

https://youtu.be/M 2bJqfkfho

Online Consultation App --Teacher Process Video

https://youtu.be/roEM_NUMG0c

\section{References}

[1] PACUCOA. (2012). Manual of Accreditation. In PACUCOA, Manual of Accreditation. PACUCOA. https://doi.org/10.7719/ipair.vli1.25

[2] Statistica. (2017). Statistica. Retrieved November 25, 2017, from The Statistical Portal: https://www.statista.com/statistics/274774/forecast-of-mobile-phone-users worldwide/

[3] California State University. (2017). Fresno state. Retrieved November 25, 2017, from Fresno State: http://www.fresnostate.edu/ academics/facultyaffairs/documents/338.pdf.

[4] Tutorials Point. (2017). SDLC V Model. Retrieved November 25, 2017, from Tutorial Point Simply Easy Learning: https://www.tutorialspoint.com/sdlc/sdlc v model.htm.

[5] Marzita Mansor, Wan Adilah Wan Adnan, Natrah Abdullah (2019) Personalized Reading: Developing User-Describing Profile for Slow Learner Children, Internaional Journal of Interactive Mobile Technologies, Vol. 13, No. 7, 2019, https://doi.org/10.3991/ijim.v13i07. $\underline{10775}$

[6] Ning Zhang, Bo Liu, (2019) "Alignment of business in robotic process automation", International Journal of Crowd Science, Vol. 3 Issue: 1, pp.26-35, https://doi.org/10.1108/ijcs09-2018-0018

[7] Kolsoum Deldar, Kambiz Bahaadinbeigy, Seyed Mahmood Tara.Teleconsultation and Clinical Decision Making: a Systematic Review. Acta Inform Med. 2016 Jul 16; 24(4): 286-292. Published online 2016 Aug. https://doi.org/10.5455/aim.2016.24.286-292.

[8] Ani Liza Asnawi, Amalina Ahmad, Nor Fadhillah Mohamed Azmin, Kamsiah Ismail, Ahmad Zamani Jusoh, Siti Noorjannah Ibrahim, Huda Adibah Mohd Ramli (2019). The Needs of Collaborative Tool for Practicing Pair Programming in Educational Setting. International Journal of Interactive Mobile Technologies, Vol. 13, No. 7, 2019 https://doi.org/10.3991/ijim.v13i07.10722

[9] Kennedy, E. K., Cameron, R. J., \& Monsen, J. (2009). Effective Consultation in Educational and Child Psychology Practice: Professional Training for Both Competence and Capability. School Psychology International, 30(6), 603-625. https://doi.org/10.1177/ $\underline{0143034309107079}$

[10] Norhasyimah Hamzah, Noor Dayana Abd Halim, Mohammad Hafiz Hassan, Arihasnida Ariffin (2019) Android Application for Children to Learn Basic Solat, International. https://doi.org/10.3991/ijim.v13i07.10758

[11] Kevin C. Moffitt, Andrea M. Rozario, and Miklos A. Vasarhelyi (2018) Robotic Process Automation for Auditing. Journal of Emerging Technologies in Accounting: Spring 2018, Vol. 15, No. 1, pp. 1-10. https://doi.org/10.2308/jeta-10589

[12] Somayya Madakam, Rajesh M Holmukhe, Durgesh Kumar Jaiswal (2019) The Future Digital Work Force: Robotic Process Automation (RPA). Journal of Information Systems and Technology Management: Vol 6. On-line versiISSN 1807-1775. https://doi.org/10. 4301/s1807-1775201916001

[13] Paolo Zanaboni, Simonetta Scalvini, Palmira Bernocchi, Gabriella Borghi, Caterina Tridico and Cristina Masella (2009). Teleconsultation service to improve healthcare in rural ar- 
eas: acceptance, organizational impact and appropriateness. BMC Health Services Research.Published: 18 December 2009: https://doi.org/10.1186/1472-6963-9-238

[14] Shasta M. Ihorn \& Prerna Arora (2018) Teleconsultation to Support the Education of Students with Visual Impairments: A Program Evaluation, Journal of Educational and Psychological Consultation, 28:3, 319-341, https://doi.org/10.1080/10474412.2018.1425878

\section{Authors}

Eliza B. Ayo, PhD: Works with Computer Education Department Centro Escolar University, 9 Mendiola St., San Miguel, Manila City Email: ebayo@ceu.edu.ph

Diane Montero: Diana is a consultant and project manager at StratX ExL. She's responsible for the design, delivery and facilitation of StratX ExL learning and development programs. Email: drumontero@ceu.edu.ph

Dianne Dote: Works with St. Jude College, Manila Philippines Email: djdote. 2013@gmail.com

Liza Villanueva: Works with Our Lady of Perpetual Help, Manila Philippines. Email:god_cares_4uandme@yahoo.com

Celia Verano, PhD: Works with Arellano University, Manila Philippines. Email: profverano@yahoo.com

Article submitted 2019-07-15. Resubmitted 2020-03-01. Final acceptance 2020-03-04. Final version published as submitted by the authors. 